\title{
POESIA EM REDE: POESIA PORTUGUESA EM BLOGUES E SÍTIOS*
}

\author{
Manuel Portela* \\ Rita Grácio*
}

\begin{abstract}
RESUMO: Este artigo parte de um levantamento do uso de meios electrónicos em rede para a produção e publicação de poesia em Portugal. Consideramos quer a poesia publicada e distribuída digitalmente, quer a poesia electrónica em sentido estrito, isto é, a poesia que depende de códigos de programação e de aplicações de software específicas. A nossa abordagem combina uma análise específica do meio e das propriedades formais das obras e publicações com uma análise sociológica das relações sociais de produção em diversos grupos e comunidades. Estamos interessados em observar de que modo as práticas de escrita têm vindo a utilizar o meio digital para criar, publicar e distribuir poesia. O espaço de escrita electrónico oferece um canal e um suporte alternativo ao meio mais dispendioso da impressão e distribuição em papel. Além disso, alarga as materialidades da literatura a formas e práticas intermédia que tiram partido das capacidades de convergência dos meios de comunicação promovidas pela digitalidade. Tentamos compreender ainda a dinâmica social deste campo literário particular e das suas redes de interacção, na medida em que reflectem, contestam ou transformam o campo literário mais amplo.
\end{abstract}

PALAVRAS-CHAVE: Poesia electrónica portuguesa. Publicação em linha. Blogues de poesia. Campo literário. Redes sociais.

\section{Investigação das práticas literárias em linha}

A investigação sobre as materialidades e práticas tecno-sociais originadas pelos média digitais tem acompanhado o seu desenvolvimento desde o início da década de 1990. A generalização de ferramentas da Web 2.0 durante a última década acentuou a socialização dos meios electrónicos de produção cultural, criando um vasto mediaram a na Internet. Como consequência, constituíram-se diversos novos campos de investigação, os quais, por seu turno, têm vindo a reconfigurar

\footnotetext{
Artigo produzido no âmbito do 'Observatório de Poesia Electrónica Portuguesa', integrado no projecto 'Novas Poéticas de Resistência: O Século XXI em Portugal' do Centro de Estudos Sociais da Universidade de Coimbra, coordenado por Graça Capinha. Projeto financiado pela Fundação para a Ciência e a Tecnologia, com a referência FCT - FCOMP-01-0124-FEDER-007264.

Universidade de Coimbra (Centro de Literatura Portuguesa). Imeio: mportela@fl.uc.pt

"Universidade de Coimbra (Centro de Estudos Sociais). Imeio: ritagracio@ces.uc.pt
}

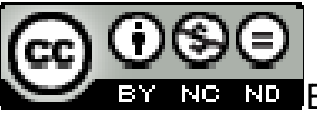

Texto Digital, Florianópolis, v. 8, n. 2, p. 302-336, jul./dez. 2012. ISSNe: 1807-9288 
os currículos de ensino em muitas das áreas tradicionais e levaram à emergência de novas disciplinas. Ciberjornalismo, informática social, linguística da internet, estudos de literacia digital, estética digital, sociologia das redes electrónicas e outros campos tornaram-se na última década e meia temas de revistas, colóquios, disciplinas, cursos e projectos de investigação. ${ }^{1}$ A internet ampliou o espaço económico, social e político, e aumentou consideravelmente os processos de intermediação e de retroalimentação entre seres humanos e máquinas computacionais nas práticas sociais e na reprodução cultural. Este espaço de escrita electrónico foi também apropriado como um meio de expressão para práticas artísticas e literárias, e como um espaço tecnocultural de experimentação com as representações. A literatura electrónica e as artes digitais são exemplos da extensão e reconfiguração dos domínios artísticos criados pelos novos média.

Um conjunto de estudos sobre as materialidades digitais da comunicação desencadeados pelas mudanças em curso deu origem a contributos significativos para o conhecimento da mediação tecnológica (Kittler, 1999 e 2010; Bolter e Grusin, 2000; Hansen, 2006a e 2006b; Zielinski, 2006; Gitelman, 2008; Manovich, 2001 e 2008; Kirshenbaum, 2008; Hayles 2002, 2005, 2008 e 2012; Drucker, 2009). Os estudos dos novos média das duas últimas décadas acrescentaram um novo capítulo à teoria dos média, obrigando-nos a observar de novo as relações entre os seres humanos e os seus aparatos tecnológicos. Existe actualmente uma vasta bibliografia sobre redes e ferramentas electrónicas estudadas a partir de

\footnotetext{
1 First Monday (fundada em 1996; publicada pela University of Illinois at Chicago, http://firstmonday.org/htbin/cgiwrap/bin/ojs/index.php/fm/index), Journal of Computer-Mediated Communication (fundada em 1995, publicada pela School of Library \& Information Science at the

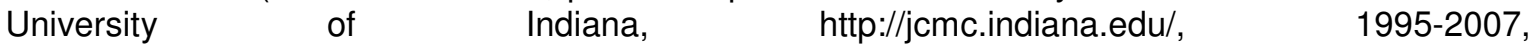
http://www3.interscience.wiley.com/journal/117979306/home, 2007-2010) e Language@Internet (fundada em 2004; publicada pela Digital Peer Publishing, North Rhine-Westphalia, e pelo University Libraries Center em Colónia, http://www.languageatinternet.de/), por exemplo, são três revistas em linha que se centram na comunicação mediada por computador a partir de perspectivas culturais, sociológicas e linguísticas. Na última década, inúmeros projectos de investigação têm sido dedicados às literacias digitais. Veja-se, a título de exemplo, o projecto Transliteracies: Research in the Technological, Social, and Cultural Practices of Online Reading (iniciado em 2005, na University of California at Santa Barbara, http://transliteracies.english.ucsb.edu/category/research-project). Uma lista de cerca de 50 programas de disciplinas dedicadas aos média digitais, criados durante a última década (representando perspectivas técnicas, artísticas, literárias, textuais, históricas, sociológicas, antropológicas e filosóficas) pode ser consultada no URL http://www.ci.uc.pt/diglit/DigLitWebHumanidadesDigitais.html\#1ProgramasSyllabi
} 
uma perspectiva sociológica, geralmente tratando questões de representação social e auto-representação com metodologias de análise do discurso (Gurak et al., 2004; Androutsopoulos e Beißwenger, 2008; Morrison, 2008). Há também um crescente corpo de pesquisa sobre a história e as materialidades digitais e formais da literatura electrónica (Aarseth, 1997; Glazier, 2002; Morris e Swiss, 2006; Funkhouser, 2007; Hayles, 2008; Simanowski et. al., 2010) e sobre o uso da linguagem em interacções mediadas por computador (Kress, 2004; Crystal, 2006). ${ }^{2}$ No entanto, a literatura científica sobre questões especificamente sócioliterárias no presente contexto de comunicação, ou seja, sobre as interacções entre as ferramentas web e a dinâmica social da produção literária, continua a ser escassa.

Digital Poetics (2002), de Loss Pequeño Glazier, contém uma das primeiras tentativas de mapear o campo da poesia no espaço digital. Glazier centra a sua atenção na poética dos códigos de programação como uma nova poética dos média programáveis, descrevendo a extensão da escrita à textualidade electrónica como uma extensão das práticas inovadoras da poesia do século XX. Glazier estabelece também uma ligação entre a publicação de poesia na web e o papel das pequenas editoras ao longo do século $X X$, com recurso à edição tipográfica manual, à mimeografia, à electrografia e a outras técnicas de reprodução com intervenção directa dos autores. O aumento da actividade na web na década de 1990 seria assim uma extensão natural, sob as novas condições de mediação tecnológica, de uma prática alternativa aos modos de

\footnotetext{
${ }^{2}$ Uma das revistas de maior longevidade, dedicada à tecnocultura e à poética digital, é a electronic book review, dirigida por Joseph Tabbi, em linha desde 1996 (http://www.electronicbookreview.com/). Refiram-se ainda dois e-zines internacionais recentes, exclusivamente dedicados à poesia e poética electrónica: netpoetic.com: exploring digital poetry and electronic literature (coordenado por Jason Nelson e Davin Heckman, iniciado em 2009; http://netpoetic.com/) e ELP emerging language practices (coordenado por Loss Pequeño Glazier, iniciado em 2010; http://epc.buffalo.edu/ezines/elp/). Em Portugal, refiram-se as revistas: Cibertextualidades (2006-2012, 5 volumes; publicada pelo Centro de Texto Informático e Ciberliteratura da Universidade Fernando Pessoa, http://cetic.ufp.pt/cibertextualidades/), que tem abordado a relação entre a materialidade digital e as práticas literárias; e Interact: Journal of Art, Culture, and Technology (2000-2012, 19 números; publicada pelo Centro de Estudos de Comunicação e Linguagens da Universidade Nova de Lisboa, http://www.interact.com.pt/).
} 
publicação e distribuição dominantes na economia do livro e das publicações periódicas:

\begin{abstract}
What's more, e-writing has an increased appeal since it can be nearly instantaneously transmitted to any other connected computer on the planet. Such an idea has returned a palpable sense of power of the written word. That old phrase "would you put that in writing" now suggests not just that writing adds legitimacy to an utterance but that, in the electronic realm, it can also be delivered. Similarly, it was the potential for dissemination that fuelled numerous historical writing movements, including the Soviet Samisdat, various fine and little press movements, mail art movements, the Mimeo Revolution, the photocopy press of the 1970s, "the PageMaker Press" of the 1980s, and the Zine movement of the 1990s. These are all traditions where the writer took control of the production and circulation of literature. (Glazier, 2002, p. 19)
\end{abstract}

De facto, a simplificação das ferramentas de edição web e o crescimento do número de plataformas de publicação tornaram a auto-edição e a autopublicação práticas constitutivas do espaço de escrita electrónico, em todos os domínios da escrita. Embora a designação 'poesia electrónica' refira, num sentido estrito, poesia cuja produção e leitura depende da execução de código informático, o campo de observação do 'observatório de poesia electrónica' inclui o uso do espaço de escrita electrónico para a produção de escrita poética em geral, incluindo a migração de formas e géneros de escrita não computacionais. ${ }^{3} \mathrm{~A}$ utilização de blogues e sítios web para a produção e publicação de poesia permite observar os efeitos da mediação digital ao criar uma intersecção entre novos recursos de publicação e novas ferramentas de escrita.

O estudo recente de Rita Alberto (2009) sobre poetas-bloggers portugueses analisa de forma integrada as práticas poéticas e os processos de auto-

\footnotetext{
${ }^{3}$ Apesar de algumas experiências pioneiras nas décadas de 1970 e 1980, de autores como E.M. de Melo e Castro, Pedro Barbosa e Silvestre Pestana, a produção que se pode descrever como estritamente electrónica nas duas últimas décadas continua a ser pequena. Pedro Barbosa começou a explorar a geração automática de texto na década de 1970. Os seus primeiros livros continham um conjunto seleccionado de textos automáticos produzidos por vários motores textuais. Com E.M. de Melo e Castro, Pedro Barbosa foi também um dos primeiros teóricos portugueses sobre o uso de computadores na criação literária. Os seus primeiros artigos foram posteriormente recolhidos na obra Ciberliteratura: Criação Literária e Computador (1996). Antero de Alda e Rui Torres são, actualmente, os dois principais autores de poesia digital em Portugal. Do projecto de investigação em curso 'Po.Ex 70-80: Arquivo Digital da Literatura Experimental Portuguesa' (2010-2013; http://www.po-ex.net/) faz parte a recriação e emulação dos primeiros poemas electrónicos portugueses realizados nos anos 70 e 80 .
} 
representação e de identidade na produção de poesia em linha. Rita Alberto opta por um estudo situado dos seus objectos, analisando as práticas poéticas enquanto práticas sociais e as teorias poéticas enquanto discursos. Um excerto do resumo explica o essencial da sua abordagem: 'A investigação centra-se em quatro hipóteses fundamentais: a) a importância das redes sociais na construção das identidades e trajectórias dos/as poetas portugueses/as; b) a relevância do papel da blogosfera na reformulação do poder, da autoridade e da legitimidade literários; c) a existência de um discurso teórico-político sobre o acto de escrever por parte destes/as poetas-bloggers; e d) a existência de uma percepção crítica das instituições do cânone literário (editoras, prémios, críticos literários, media impressos)' (Alberto, 2009, p. iii). Esta integração de uma abordagem sociológica com uma abordagem poética está geralmente ausente dos estudos dos usos artísticos dos novos média, que tendem a centrar-se nas questões tecnológicas e formais. Por outro lado, a produção analisada no estudo de Rita Alberto diz respeito apenas a produção electrónica num sentido lato.

Dois aspectos se destacam das suas conclusões: por um lado, o facto de os blogues funcionarem como ferramentas tecno-sociais de negociação das identidades e práticas poéticas que fazem a mediação entre redes sociais circunscritas e espaços institucionais de legitimação e reconhecimento mais amplos; por outro lado, a natureza contraditória dos discursos que autorepresentam a sua actividade e a sua relação com as instituições de legitimação. O conceito de 'escrita em processo' é usado por Rita Alberto para dar conta deste duplo movimento de experimentação processual com o meio, no seio de redes sociais restritas, e de construção contraditória de uma identidade poética em espaços sociais e institucionais mais vastos. ${ }^{4} \mathrm{O}$ estudo confirmou a persistência

\footnotetext{
${ }^{4}$ Embora não tenha sido possível aplicar esta metodologia à amostra de blogues e sítios que constituem o corpus do 'Observatório de Poesia Electrónica', os resultados obtidos no estudo de Rita Alberto demonstram a pertinência do método escolhido, que além de variáveis sociográficas (sexo, idade, nível de escolaridade, profissão, localização geográfica) incluiu uma entrevista aberta que permitiu descrever processos de representação e de auto-representação das práticas poéticas na blogosfera. Deste modo, a construção das identidades poéticas pode relacionar-se com a morfologia das redes sociais dos indivíduos, revelando de que modo as morfologias particulares dessas redes condicionam o acesso a recursos como reconhecimento e oportunidades (Alberto, 2009, pp. 46-52).
} 
do livro como instrumento de legitimação da actividade e da identidade poética, quer no espaço social em geral, quer no discurso dos próprios agentes:

Se predomina nestes discursos uma valorização positiva do blog (conflitos e tensões quase não são referidos), em todos os discursos persiste uma certa hierarquização do livro em relação ao blog. Ainda que o blog pareça democratizar práticas de escrita e leitura, persistem alguns conceitos elitistas de público e de poeta. (Alberto, 2009, pp. 68-69)

\section{Dinâmicas de escrita e publicação web}

Durante a primeira fase do projecto, o Observatório de Poesia Electrónica (Observatório) centrou a sua atenção em questões metodológicas. Com a ajuda de diversos motores de pesquisa e das listas de ligações constantes dos blogues de poesia identificados, levámos a cabo um levantamento do campo da produção de poesia no espaço de escrita electrónico em Portugal, com o objectivo de seleccionar um corpus para observação. Neste momento, o corpus é composto por cerca de seis centenas de blogues, sítios web e revistas em linha. ${ }^{5} \mathrm{O}$ Observatório procurou também uma perspectiva teórica para articular a relação entre produção e publicação electrónica, por um lado, e produção e publicação impressa, por outro. A observação da dinâmica dessa relação, bem como os modos e meios específicos de criação e publicação electrónica foram os dois aspectos centrais na estruturação da investigação. A perspectiva adoptada combina a teoria do campo literário e cultural com a teoria e sociologia dos novos média, tomando ainda como referência de enquadramento as poéticas contemporâneas, designadamente através da ênfase nas materialidades discursivas, sonoras, visuais e tecnológicas dos processos de significação (Bernstein, 2006; Watten, 2006; Perloff, 2006; Drucker, 2006; Armand, 2007; Portela, 2009, 2010, 2011 e 2012).

O Observatório segue essencialmente duas linhas de pesquisa. Uma linha toma como objecto de investigação a poesia portuguesa que circula na blogosfera e no

\footnotetext{
${ }^{5}$ Desse corpus foram escolhidas para caracterização descritiva cinco dezenas. Sob a forma de uma base de dados, esse corpus estará acessível em linha no sítio web do Centro de Estudos Sociais no URL associado a este projecto:

http://www.ces.uc.pt/projectos/novaspoeticas/pages/portugues/homepage.php.
} 
espaço da escrita electrónico, ou seja, centra-se na utilização das plataformas de hipertexto e de hipermédia para a escrita e a publicação. A outra linha de pesquisa visa investigar a própria natureza da escrita hipertextual e hipermédia, ou seja, da poesia que é gerada através das materialidades digitais das tecnologias de comunicação e informação, e que faz uso das propriedades específicas das plataformas e aplicações informáticas como parte de sua forma literária e dos seus recursos expressivos. Em ambos os casos, observamos processos de 'remediação' (Bolter e Grusin, 2000), ou seja, a reconfiguração das formas e práticas anteriores através das propriedades do novo meio, e também processos de invenção de formas e práticas especificamente electrónicas.

A conformação do poema breve à entrada datada de um blogue, criando contiguidade entre o registo autobiográfico da entrada de diário e o registo lírico, constitui um exemplo do primeiro tipo, isto é, de adaptação de uma forma a uma matriz de publicação. A utilização de programas de animação ou de geração automática de texto é um exemplo do segundo tipo, isto é, de utilização expressiva de propriedades textuais de natureza computacional. A poesia no espaço de escrita electrónico transforma não só a economia de produção e recepção, mas a economia da criação, uma vez que a materialidade digital se torna parte das formas poéticas e dos seus recursos estilísticos e retóricos (Aarseth, 1997; Hayles, 2008). Uma linha de investigação recente tem analisado os próprios códigos computacionais como parte dos novos recursos e linguagens poéticas (Bootz, 2006; Cayley, 2006, 2012; Wardrip-Fruin, 2009; Marino,2010).

Analisar a poesia portuguesa produzida e distribuída no espaço electrónico é analisar de que modo a categoria 'poesia' é reproduzida e transformada pelo espaço electrónico, tanto nos processos criativos como nos processos de reconhecimento e legitimação pública. As categorias que definem a produção e recepção nos meios impressos (autor, editor, leitor, crítico) são parcialmente reconfiguradas nas suas funções e relações quando aplicadas ao meio electrónico. A economia da produção no espaço electrónico difere da economia de mercado e das instâncias de controlo dos meios impressos. Os estágios de 
produção alteram-se: a escrita aproxima-se da publicação e a leitura pode tomar a forma de escrita. Autopublicando-se, o autor furta-se à mediação e ao controlo editorial. Comentando o escrito, o leitor deixa um rastro quase imediato por meio de um texto que responde, de forma mais ou menos elaborada, a um texto lido. $A$ instantaneidade e sincronicidade da comunicação digital aproximam produção e recepção também na comunicação escrita. A cultura digital em rede introduziu ferramentas de software e comportamentos sociais que fazem com que a escrita se aproxime, por vezes, da interacção oral, reduzindo o tempo de resposta da comunicação assíncrona por escrito e incentivando formas multimodais de resposta e de interacção. Nestes casos, não se pode pensar no blogue e no sítio web apenas como um meio alternativo à impressão, mas sim como uma nova prática de escrita, que gera as suas convenções e desenvolve a sua própria retórica.

A inclusão de um blogue, sítio web ou outra forma de publicação electrónica neste estudo depende do reconhecimento da presença de pelo menos uma destas duas intenções explícitas: em primeiro lugar, da intenção de construir um espaço alternativo para a publicação; em segundo lugar, da intenção de explorar a natureza material desse espaço de escrita e leitura como um meio de expressão e comunicação ou como um meio para a experimentação com novas formas e novas práticas. Por isso, é importante investigar também a relação entre as identidades electrónicas poéticas e as identidades poéticas impressas no modo como são construídas por produtores e receptores. Embora o espaço electrónico possa surgir como espaço alternativo para a criação e publicação, ele funciona ao mesmo tempo dentro dos processos gerais da mediação discursiva e tecnológica da reprodução social. Assim a produção e distribuição electrónica intersecta-se com a produção, distribuição e recepção impressa.

Este Observatório é uma primeira tentativa de analisar as intersecções entre as instâncias tradicionais de legitimação e a Internet no domínio específico da produção de poesia. Uma investigação sistemática deveria permitir responder a algumas destas perguntas. Qual é a hierarquia entre a publicação impressa (sob 
a forma de livro ou revista) e a publicação electrónica para os/as poetas estabelecidos/as e para os/as autores/as emergentes? Que espaços materiais e institucionais para a criação e publicação foram abertos pelos novos média? Existem no espaço electrónico formas de produção, distribuição, leitura e crítica que diferem das formas que dominam os média impressos? Ou será o meio electrónico apenas uma extensão dos mecanismos mantidos pelas forças interdependentes do mercado, das universidades e dos meios de comunicação? Como é que o espaço de escrita electrónico funciona em relação às instituições de legitimação? Por outro lado, que mudanças nas formas e práticas poéticas derivam da materialidade e da economia de produção e distribuição electrónica? Este projecto constitui uma primeira tentativa de cartografar as práticas e formas existentes e discernir algumas das tensões e contradições que as estruturam.

Os blogues, sítios web e revistas electrónicas pesquisados neste estudo foram analisados de acordo com quatro dinâmicas:

(1) Dinâmica de publicação. Neste caso, o objectivo é olhar para a sua autodefinição em relação a outros meios de publicação, ou seja, se são usados explicitamente pelos seus autores como um meio alternativo à publicação impressa (como seria a publicação numa revista de poesia ou sob a forma de livro). Há projectos colectivos e individuais em que essa intencionalidade é claramente reconhecível.

(2) Dinâmica de produção. Neste caso, observamos em que medida a exploração criativa das propriedades do meio transforma o blogue, o sítio web ou a revista electrónica não só num meio de publicar formas poéticas convencionais reconhecíveis, mas também num meio de transformação e invenção de formas poéticas, ou seja, formas que exploram propriedades específicas do meio. Isto é o que acontece, por exemplo, nos modos visuais ecfrásticos que exploram dinâmicas de relação entre imagem e texto verbal graças às possibilidades de publicação integrada de texto alfanumérico e de ficheiros de imagem. É também o caso da poesia digital, executada por 
aplicações de software específicas ou por código de programação desenvolvido pelos próprios autores. Encontrámos quer formas características da tradição impressa, quer formas híbridas que combinam géneros textuais impressos e certos aspectos da textualidade electrónica, quer ainda formas electrónicas que dependem fortemente da materialidade digital. Em todos estes casos, encontramos graus variáveis de intervenção sobre a própria linguagem verbal e graus variáveis de integração entre a dimensão discursiva e as restantes dimensões materiais e técnicas.

(3) Dinâmica de representação e auto-representação. Neste caso, analisamos os discursos programáticos ou de autodescrição da própria actividade e os discursos sobre o campo cultural da poesia e da produção literária em geral. A nossa pesquisa mostrou que uma descrição formal e tecnológica, útil para a compreensão de certos efeitos dos novos média sobre as formas estéticas, não é suficiente para dar conta da natureza socialmente situada das práticas de escrever e publicar poesia em meio electrónico. Esta análise dos discursos permite fazer uma descrição mais estratificada e mais densa da prática enquanto acto social. Em alguns casos, o trabalho etnográfico de entrevista realizado por Rita Alberto (2009) permitiu descrever as redes de interacção pessoal que sustentam o processo de escrita, na história individual e nas práticas presentes, e os processos de valorização simbólica que produzem e sustêm as identidades poéticas.

(4) Dinâmica de socialização. A crescente disponibilidade e usabilidade das plataformas web significa que a publicação de ficheiros em linha já não é condicionada pela escassez de recursos de produção e distribuição que define o meio de publicação impressa. As ferramentas digitais favorecem padrões de socialização da produção e da recepção que reflectem a dinâmica das redes sociais mediadas pelas redes electrónicas, nas suas várias escalas. Este é um outro aspecto da prática de escrita e publicação em plataformas electrónicas que merece atenção: a criação de comunidades de leitura e de escrita empenhadas em explorar as capacidades 
comunicativas do meio para a partilha de modos de escrita e para a definição de identidades.

$\mathrm{Na}$ descrição da relação entre o espaço de escrita electrónico e os circuitos de produção, distribuição e recepção do espaço de escrita impresso, e em particular com as formas de legitimação que estruturam o campo literário, há portanto várias dinâmicas a considerar: a dinâmica económica e social da publicação e circulação de discursos poéticos no espaço electrónico (dinâmicas de publicação e socialização); a dinâmica formal interna de reprodução e transformação das formas poéticas por efeito do novo meio de comunicação (dinâmicas de produção); e a dinâmica discursiva de percepção, reconhecimento e legitimação de um conjunto de formas, práticas e agentes (dinâmicas de representação e auto-representação). Numa primeira etapa de análise, centramos a atenção na publicação e produção. Uma etapa da análise posterior deverá relacionar os modos de produção e publicação com as práticas discursivas, e elaborar uma descrição mais densa das relações entre as várias camadas na constituição e estruturação da poesia produzida e publicada electronicamente enquanto um conjunto de práticas heterogéneas que não podem ser caracterizadas apenas de acordo com especificidade no uso do meio.

\section{Uma poética de blogues e sítios web}

Depois de considerarmos várias possibilidades de categorizar os blogues e sítios pesquisados, decidimos usar a presença da própria materialidade digital nas publicações como principal critério. Parecia mais produtivo analisar o grau de interacção entre o uso dos média digitais e a transformação de formas e práticas poéticas, do que postular uma oposição a priori entre meio impresso e meio digital. Além disso, este critério permitia-nos distinguir a presença do meio electrónico ao nível da produção, da distribuição e da recepção. Esta classificação teria a vantagem teórica adicional de permitir observar a dinâmica entre a poesia em meio impresso e poesia em meio digital tanto de um ponto de vista formal, como de um ponto de vista sociológico. Uma vez caracterizados os blogues e 
sítios quanto à digitalidade, a análise da identidade de grupo e das dinâmicas de grupo poderia depois ser relacionada com manifestações específicas do uso e exploração criativa das materialidades da linguagem e do meio digital. Para a primeira etapa de análise, os vários blogues, sítios web e revistas electrónicas que compõem o corpus seleccionado foram classificados em três grupos, de acordo com o grau de presença do meio digital na produção, distribuição e recepção [cf. Quadro 01]. Embora aquelas distinções não sejam inteiramente válidas na maioria dos blogues e sítios - que incluem exemplos que poderiam ser incluídos em pelo menos dois grupos -, a tipologia pareceu-nos suficientemente genérica para agregar a maioria das publicações electrónicas identificadas.

\begin{tabular}{|c|c|c|c|c|c|c|}
\hline \multirow{2}{*}{$\begin{array}{l}\text { Presença da } \\
\text { digitalidade }\end{array}$} & \multicolumn{2}{|c|}{ Grupo A } & \multicolumn{2}{|c|}{ Grupo B } & \multicolumn{2}{|c|}{ Grupo C } \\
\hline & Impresso & Electrónico & Impresso & Electrónico & Impresso & Electrónico \\
\hline Produção & $X$ & $(x)$ & $(x)$ & $x$ & & $x$ \\
\hline Distribuição & $X$ & $x$ & $x$ & $x$ & & $x$ \\
\hline Recepção & $\mathrm{X}$ & $x$ & $x$ & $x$ & & $x$ \\
\hline $\begin{array}{l}\text { Aspectos } \\
\text { materiais e } \\
\text { formais das } \\
\text { obras }\end{array}$ & \multicolumn{2}{|c|}{$\begin{array}{l}\text { O espaço de escrita } \\
\text { electrónico é usado como } \\
\text { mera extensão ou substituto } \\
\text { da materialidade impressa. }\end{array}$} & \multicolumn{2}{|c|}{$\begin{array}{l}\text { Presença de algumas } \\
\text { características multimédia } \\
\text { ou hipermédia e exploração } \\
\text { da visualidade gráfica. }\end{array}$} & \multicolumn{2}{|c|}{$\begin{array}{l}\text { A composição é } \\
\text { determinada pelo } \\
\text { software. As obras têm de } \\
\text { ser executadas pelos } \\
\text { programas. }\end{array}$} \\
\hline
\end{tabular}

Quadro 1 - A presença da digitalidade

Grupo A. Inclui a publicação electrónica de formas textuais que são semelhantes às formas textuais impressas. Neste caso, o seu carácter 'electrónico' reflecte-se sobretudo na distribuição e recepção. O seu modo de produção não está dependente de formas específicas de textualidade digital, a não ser na medida em que são usadas as funções básicas de processamento e edição de texto das aplicações. O meio digital funciona como um meio de publicar e distribuir uma gama de géneros e formas que migraram do meio impresso, ou cuja origem está nas convenções do texto impresso, ou cujo destino poderá vir a estar também nesse meio. A transcrição frequente de poemas de autores consagrados é um exemplo deste tipo de utilização, assim como o são o uso das estruturas do verso e da estrofe. 
No Grupo A, incluímos blogues e sítios web cuja dimensão digital se encontra principalmente nos níveis de distribuição e recepção. Embora os autores estejam conscientes do meio electrónico como um novo espaço publicação, recorrem predominantemente a formas e convenções estabelecidas pela publicação impressa. Estes blogues e sítios poderiam ser descritos como uma remediação específica de géneros e formas poéticas tradicionais. O seu repertório retórico e seus modos de composição não dependem, em geral, de propriedades digitais. Isto é particularmente verdadeiro para os blogues e sítios que se definem como espaços alternativos ao modo de publicação impresso. É também verdadeiro para aqueles que publicam antologias e selecções de poemas de outros autores, nomeadamente de escritores consagrados. A plataforma electrónica é utilizada principalmente para a produção de uma identidade individual ou social através de uma selecção representativa que se torna significante de um determinado gosto ou sensibilidade. Ou, quando se trata de uma obra original, estes espaços são usados para distribuir e publicar formas tradicionais num novo meio.

Grupo B. Inclui a publicação electrónica de formas textuais que fazem uso de algumas propriedades da textualidade digital (na tipografia, na paginação, e na integração das representações verbais e pictóricas, de carácter visual ou audiovisual). Neste caso, além da distribuição e da recepção, a textualidade electrónica também se manifesta nas propriedades formais a nível de produção. Há, portanto, um reflexo do meio na forma interna do texto, mostrando que o meio de publicação intervém como meio de produção. Embora algumas destas formas possam ser recriadas em papel, a interacção entre as ferramentas informáticas e a forma textual resultante é significativamente mais forte. As formas neste grupo poderiam ser descritas como híbridas no que diz respeito à relação que estabelecem entre formas e convenções originárias dos dois meios de inscrição.

No Grupo $B$, incluímos blogues e sítios web que fazem uso de uma série de características da materialidade digital, tais como a integração entre imagem e texto ou a exploração da visualidade e topograficalidade do ecrã. Algumas destas 
são formas, géneros e práticas - como a ekphrasis - que podemos encontrar no meio impresso, mas que tomaram uma configuração específica no meio digital. A disponibilidade de imagens digitais, juntamente com a facilidade de utilização das ferramentas Web $2.0^{6}$, têm contribuído para o desenvolvimento de formas poéticas mistas, que enfatizam a visualidade, seja através de diversos modos de integração de texto e imagem, seja através da visualidade do próprio texto verbal. Assim, as formas e géneros assumem propriedades digitais ao nível da sua forma interna, designadamente de natureza icónica, e a plataforma de edição é usada também como recurso expressivo. Embora muitas destas formas possam ainda ser reproduzidas sob forma impressa, a presença do meio - através de ficheiros multimédia, das características tipográficas e das hiperligações - impregna o nível da produção. Estas formas poéticas não são mera transcrição ou migração de material que poderia ter sido produzido em meio impresso. Incorporam especificidades das ferramentas de escrita e de publicação nos seus mecanismos simbólicos, que se tornam híbridos.

Grupo C. Inclui a publicação electrónica de formas textuais que dependem inteiramente das propriedades específicas da textualidade digital (designadamente dos programas de computador e algoritmos com que foram criados e dos programas com que têm de ser executados). Estas formas só podem existir através da execução do código que as gera. A presença do meio digital surge nos níveis de produção, distribuição e recepção. Trata-se de formas de poesia electrónica que não poderiam existir em qualquer outro meio.

No Grupo C, incluímos blogues e sítios que publicam aquilo que poderia ser descrito como literatura electrónica em sentido estrito, ou seja, aquelas obras que só podem ser realizadas através de código computacional. Apenas poderiam ter sido produzidas por ferramentas de hardware e de software específicas, e só podem ser distribuídas e lidas num ambiente informatizado. A digitalidade tornou-

\footnotetext{
${ }^{6}$ Web 2.0 é a designação genérica da forma da web a partir do momento em que as diferentes plataformas de edição e publicação passaram a permitir uma produção de conteúdos descentralizada e directa dos utilizadores. A generalização de wikis, blogues e outras ferramentas de edição colaborativa, assim como da linguagem XML, ocorridas ao longo da última década, representam aplicações e usos típicos da Web 2.0.
} 
se a principal matéria na definição e caracterização formal de tais obras, como é o caso dos poemas animados que usam linguagem ActionScript ou de obras de geração automática de texto que usam motores textuais para a produção de enunciados linguísticos e de combinatórias multimédia. Nestas obras a materialidade digital mudou a forma do poema. O próprio software tornou-se uma camada explicitamente usada na composição da obra e passou a fazer parte da sua retórica textual. As obras programadas, como as que têm sido criadas por Rui Torres, pertencem a esta categoria (Portela, 2012).

Nos Grupos A e B encontramos projectos individuais e colectivos que podemos descrever como modos de publicação alternativa a uma revista ou livro impressos. Usam a distribuição electrónica para superar os constrangimentos económicos da produção impressa. Ao mesmo tempo, encontramos exemplos de escrita individual em processo, que exploram a dimensão processual e comunitária do meio, sem qualquer referência a esse horizonte de reconhecimento da publicação impressa. No que diz respeito à natureza das formas e linguagens poéticas que se desenvolvem em ambos os casos, vemos a coexistência de formas e géneros tradicionais, produzidos dentro de discursos poéticos convencionais, com géneros e formas experimentais, produzidos com maior consciência da produtividade exploratória da língua e do novo meio nas suas interacções.

É principalmente nas categorias A e B que a análise das suas autorepresentações como discursos poéticos nos permitirá entender a dinâmica entre os modos de produção impressa e os modos de produção electrónica. A categoria C mantém um tipo diferente de relação com a produção impressa, uma vez que não pressupõe uma dinâmica de concorrência e alternativa, mas visa transformar a própria percepção da linguagem e das formas poéticas como consequência da textualidade digital. De qualquer modo, mesmo neste caso pode ser observada a questão da legitimação das práticas, já que continuam a ser escassos os textos que os reconhecem como 'literatura' ou 'poesia'. 
Estabelecidos estes critérios para a recolha e descrição de uma amostra representativa de blogues, sítios web e revistas electrónicas, a tarefa subsequente do Observatório de Poesia Electrónica Portuguesa consiste em (1) analisar as suas características materiais enquanto textos publicados em formato electrónico; (2) analisar as suas auto-representações enquanto discursos poéticos; e (3) descrever, através de estudos de casos exemplificativos, as dinâmicas em curso de criação, publicação, recepção e legitimação da poesia na esfera pública electrónica.

\section{A presença do meio nas plataformas e ferramentas: redefinindo as convenções}

Nesta secção observamos brevemente alguns modos de ancoragem do discurso e da linguagem poética na materialidade do meio digital. A presença do meio digital nas publicações (blogues, sítios, revistas) manifesta-se, desde logo, no desenho gráfico e nas funcionalidades que as plataformas e os respectivos modelos permitem. Como a maior parte dos autores e autoras recorre a matrizes disponíveis em plataformas de publicação de uso livre, muitos aspectos formais dos textos na sua disposição gráfica e na sua arquitectura hipertextual são determinados pela codificação prévia das folhas de estilo CSS (Cascading Style Sheets), com um grau mais ou menos limitado de personalização. Este facto constitui, aliás, um dos aspectos específicos da cultura digital, na qual a camada gerada pelo código computacional se constitui como um elemento dos processos criativos e comunicativos. Quer sejam programados de raiz, quer sejam adaptados a partir do leque de possibilidades oferecido pelas aplicações escolhidas, estes códigos computacionais ancoram a expressividade digital nas propriedades específicas do software adoptado. Daí que a descrição da sua forma digital deva ter em conta a aplicação e a matriz usada [cf. Fig. 1]. 


\section{blog com palavras ao fundo}

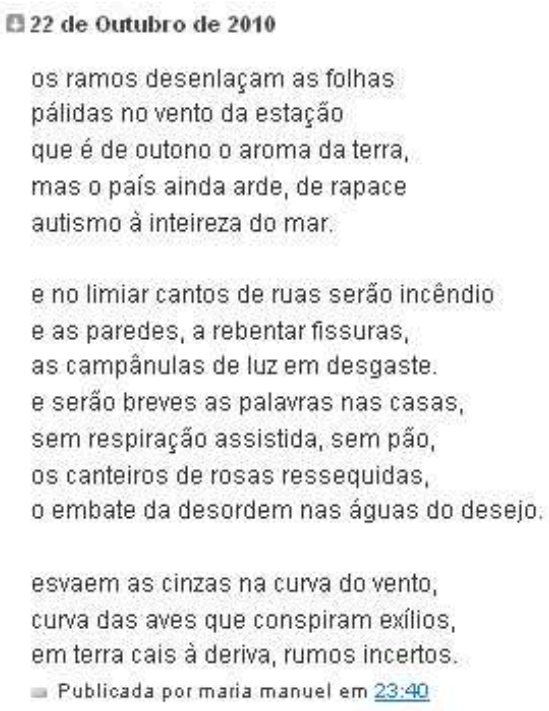

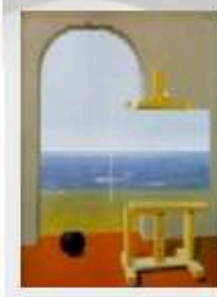

René Magritte

maria manue!

Ver o meu perfil completo

Arquivo

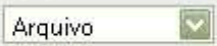

3. Seguir com o Google Rede Social

Seguidores (29) Mais x

Figura 1. Blogue com palavras ao fundo, http://blogcompalavrasaofundo.blogspot.com/. Data de publicação: 2007-2011. Autora: Maria Manuel [captura de ecrã].

Embora a consciência da mediação que o software constitui só em raros casos esteja presente de um modo auto-reflexivo, essa mediação condiciona a configuração das formas textuais publicadas electronicamente. A configuração das páginas web dos blogues sob a forma de entradas datadas compostas por uma combinação de textos e imagens é um exemplo do modo como a codificação da aplicação se pode inscrever enquanto característica formal na forma literária. Um número significativo de blogues de poesia explora modos de representação ecfrástica através da publicação conjunta de texto e imagem que se referem mutuamente. Essa referência pode funcionar apenas descritivamente ou, de uma forma indirecta, por intersecção metafórica e metonímica entre os campos verbal e visual; ou por uma combinação de modos directos e indirectos de referência. As imagens são geralmente reproduções de pinturas e desenhos, ou de natureza fotográfica [cf. Figs. 2 e 3]. 


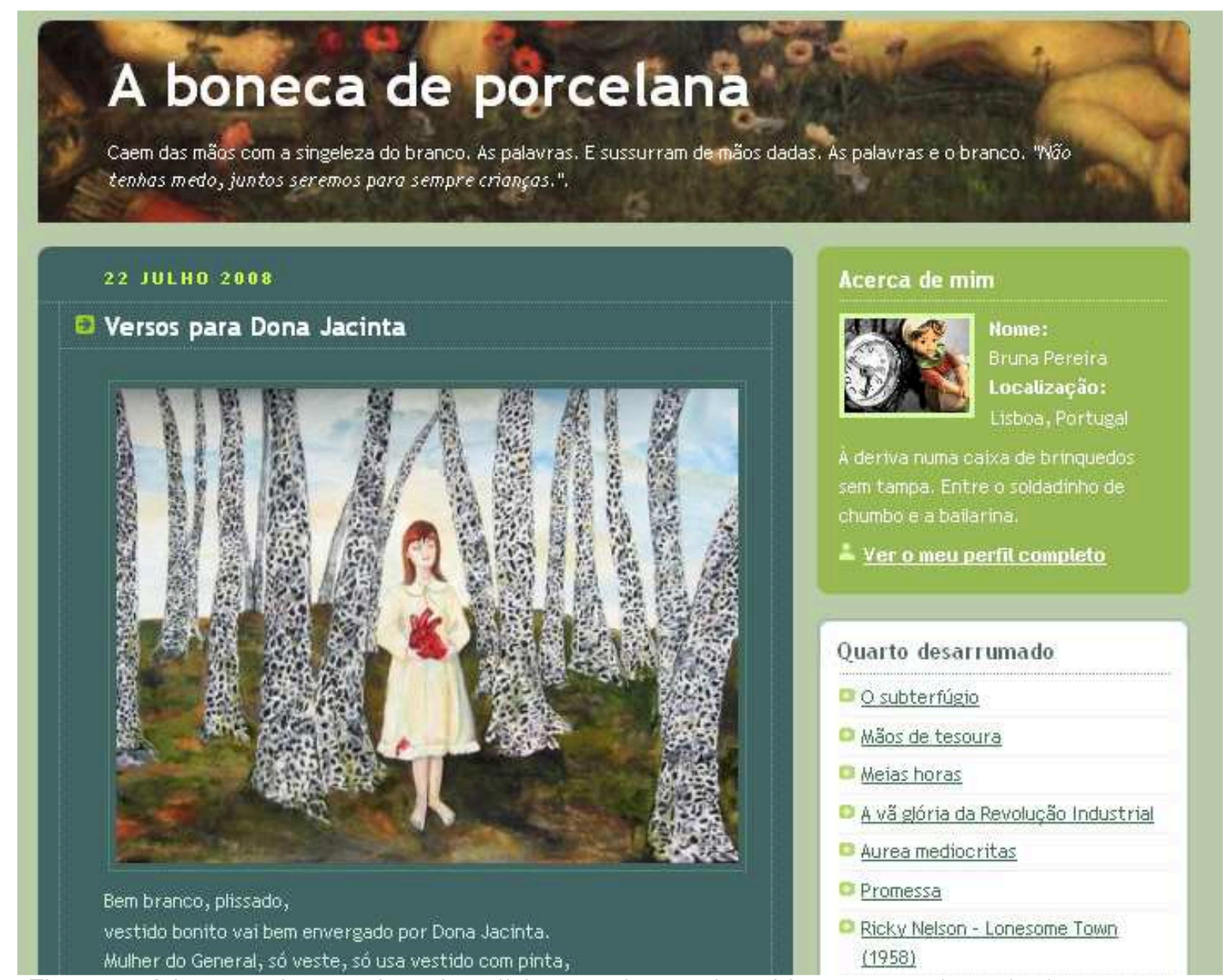

Figura 2. A boneca de porcelana, http://abonecadeporcelana.blogspot.com/2008/07/versos-paradona-jacinta.html. Data de publicação: 2006-2009. Autora: Bruna Pereira [captura de ecrã]. 


\section{BLUE MOLESKIN}

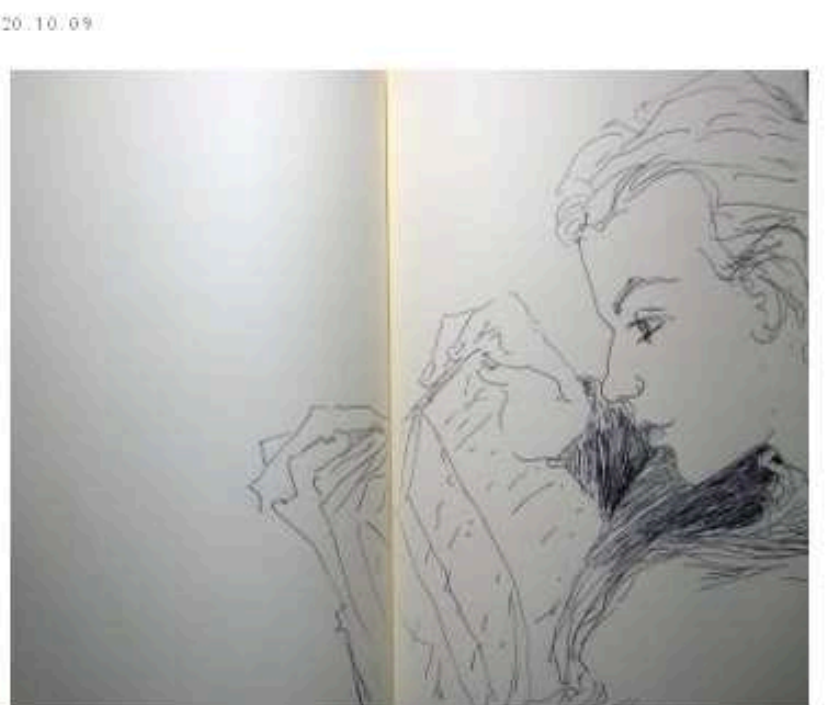

chego tarde evito a quarentena dos aflitos

arrumo o quarto a secretária os elos os sobressaltos a crónica da anemia

aliso a cervical de esguelha obseno quem se aproxima

no mouth no neck no rest

obsenoro raparigas que lêem

hoje uma caiu nos braços de um rapaz tranquilo amparámo-la até chegaro INEM
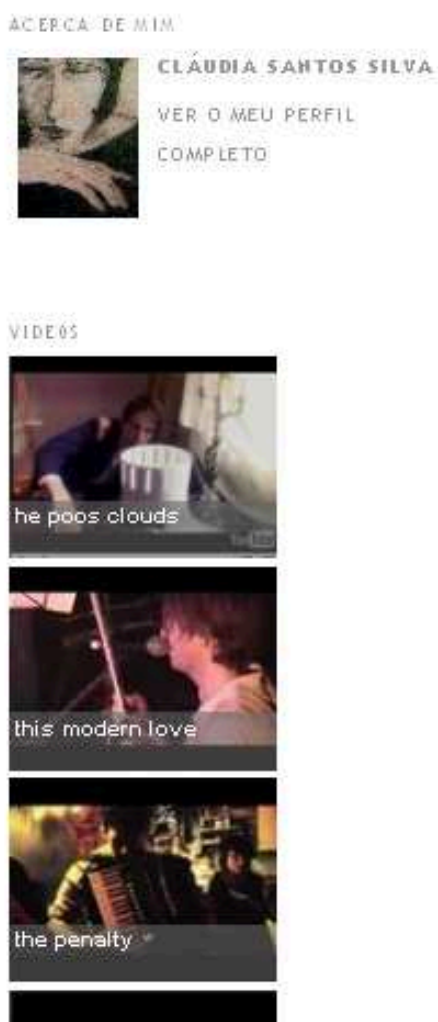

Figura 3. Blue Moleskin, http://bluemolleskin.blogspot.com/. Data de publicação: 2006-2010. Autora: Cláudia Santos Silva [captura de ecrã].

A presença do meio pode tomar ainda a forma de manipulação gráfica do espaço pixelado da superfície de inscrição do ecrã, seja na estruturação das colunas e das tabelas que organizam a visualização, seja nas propriedades dos caracteres (fonte, corpo, cor, estilo) e na sua espacialização. A intersecção entre a précodificação da plataforma escolhida e a manipulação de algumas das propriedades dos caracteres pode ser exemplificada com um excerto do blogue Com Tacto [cf. Fig. 4]. Neste caso, a inserção de tabelas e o uso de fontes, cores e corpos diferenciados para os caracteres resultou na produção de um conjunto de poemas visuais. A disposição é constrangida pela coluna definida pelo código da matriz escolhida, mas redefine as propriedades dos caracteres para além daqueles que estão na matriz. Por outro lado, estes textos visuais são enquadrados na extensão limitada da entrada diária, que funciona como a superfície de uma página funcionaria na sintaxe do códice, isto é, permitindo a 
apresentação simultânea de todos os elementos. Deste modo, tornam-se também espaciais as relações geralmente temporais da cadeia do discurso. Esta consciência da visualidade dos pixéis e das superfícies é uma das consequências da possibilidade de manipulação modular dos elementos que configuram as inscrições digitais no ecrã.

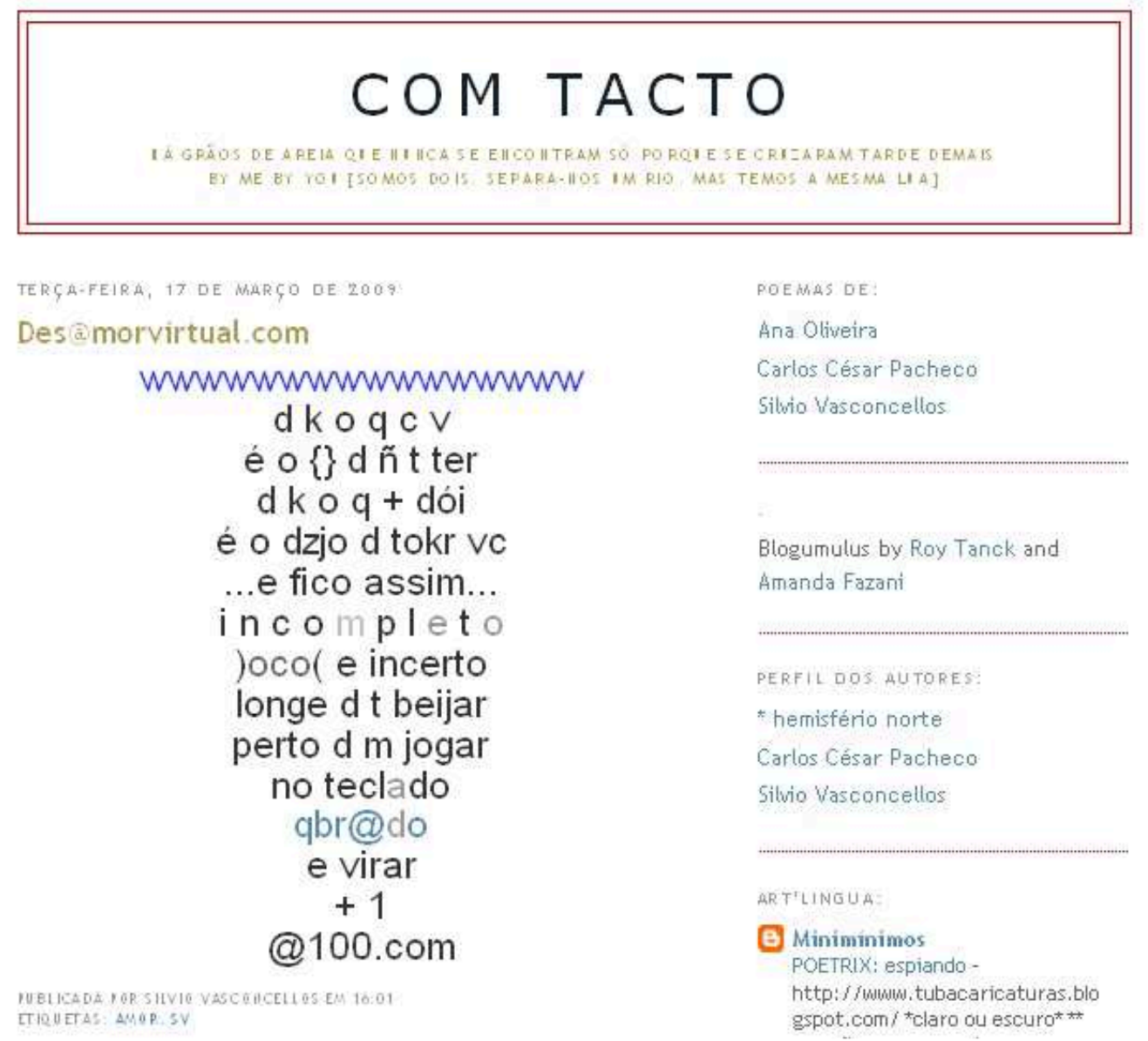

Figura 4. Com Tacto,

http://poesiaminimalista.blogspot.com/2009/03/desmorvirtualcom.html. Data de publicação: 20082010. Autores: Ana Oliveira, Carlos César Pacheco e Sílvio Vasconcellos [captura de ecrã].

A possibilidade de manipulação integrada de texto e imagem (incluindo imagem em movimento), permite ainda formas visuais de intersecção entre texto e imagem, em que os discursos verbal e pictórico perdem a sua autonomia relativa e se tornam parte do mesmo campo plástico de referência. A utilização de uma breve animação em loop constituída por uma sequência de fotografias exemplifica este modo específico de visualidade digital [cf. Fig. 5]. Neste caso, a presença do meio digital é maior e pressupõe a utilização prévia de programas de edição e manipulação de imagem e texto que resultam na produção de imagens sintéticas

Texto Digital, Florianópolis, v. 8, n. 2, p. 302-336, jul./dez. 2012. ISSNe: 1807-9288 
trabalhadas por filtros algorítmicos, e que se afastam da imagem que é mera reprodução de imagem pintada ou fotografada. Nestes exemplos acentua-se a hibridez entre literatura digital e arte digital.

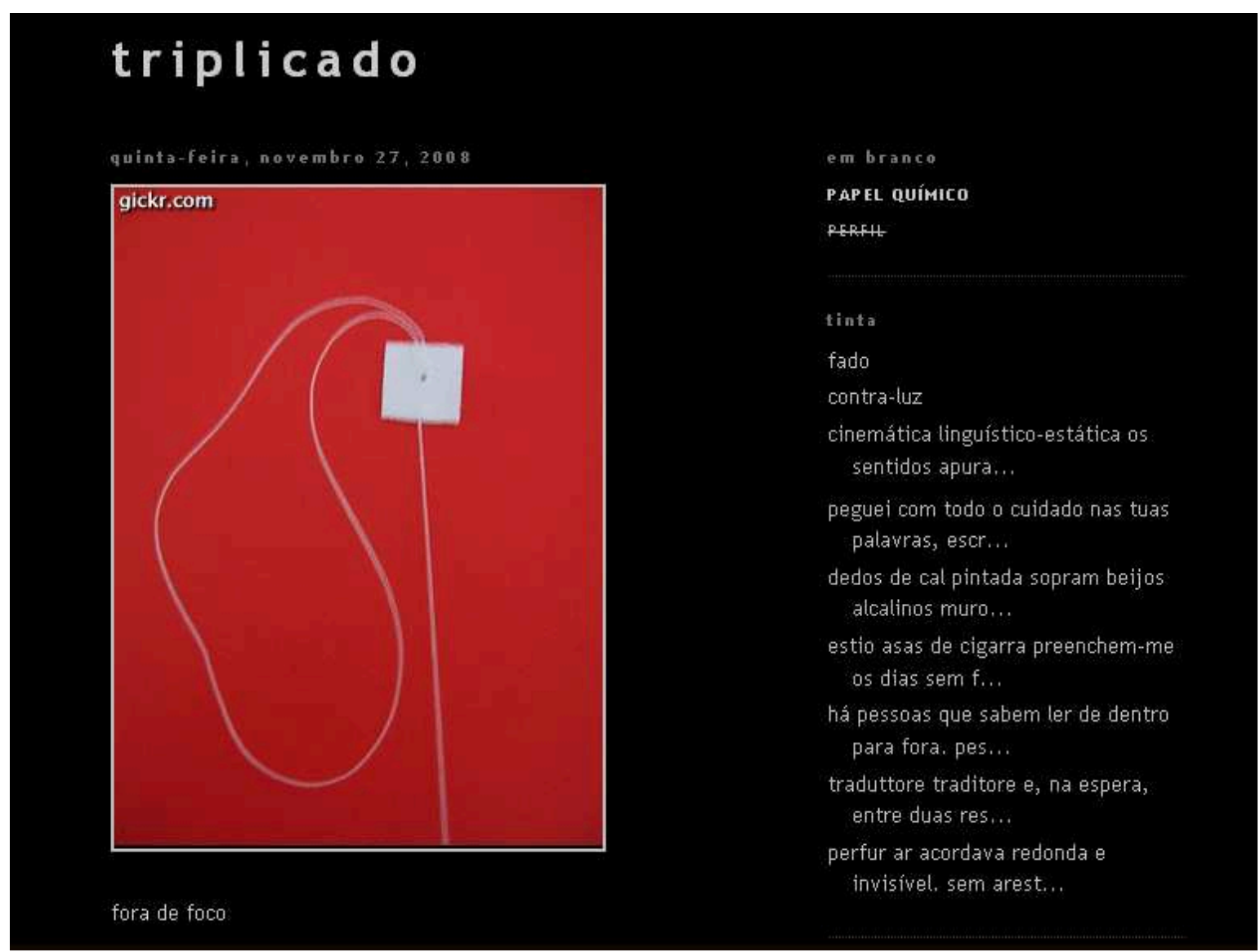

Figura 5. Triplicado, http://triplicado.blogspot.com/2008/11/blog-post.html. Data de publicação: 2006-2011 [captura de ecrã].

$\mathrm{Na}$ medida em que a diferença entre práticas artísticas depende da diferença entre os meios que as definem enquanto práticas especializadas, a crescente convergência dos média decorrente da tecnologia digital tende a produzir formas e géneros híbridos, difíceis de apreender dentro das instituições e das categorias de percepção anteriores. Se no caso da geração automática de texto ainda é possível reconhecer uma matriz literária, quando processos algorítmicos semelhantes são usados para recombinar em simultâneo imagem pictórica e texto verbal, ou texto verbal e imagem cinética, estamos perante formas de arte digital sem equivalente directo nas formas e géneros anteriores. A literatura especificamente electrónica encontra-se frequentemente nesta posição. É o caso de sítios web de autores como Antero de Alda ou Rui Torres, cuja produção 
incorpora plenamente o hibridismo inter-artístico resultante da convergência de meios em poemas programados inteiramente multimodais, que combinam imagem, texto verbal, voz, música e vídeo [cf. Figs. 6 e 7].

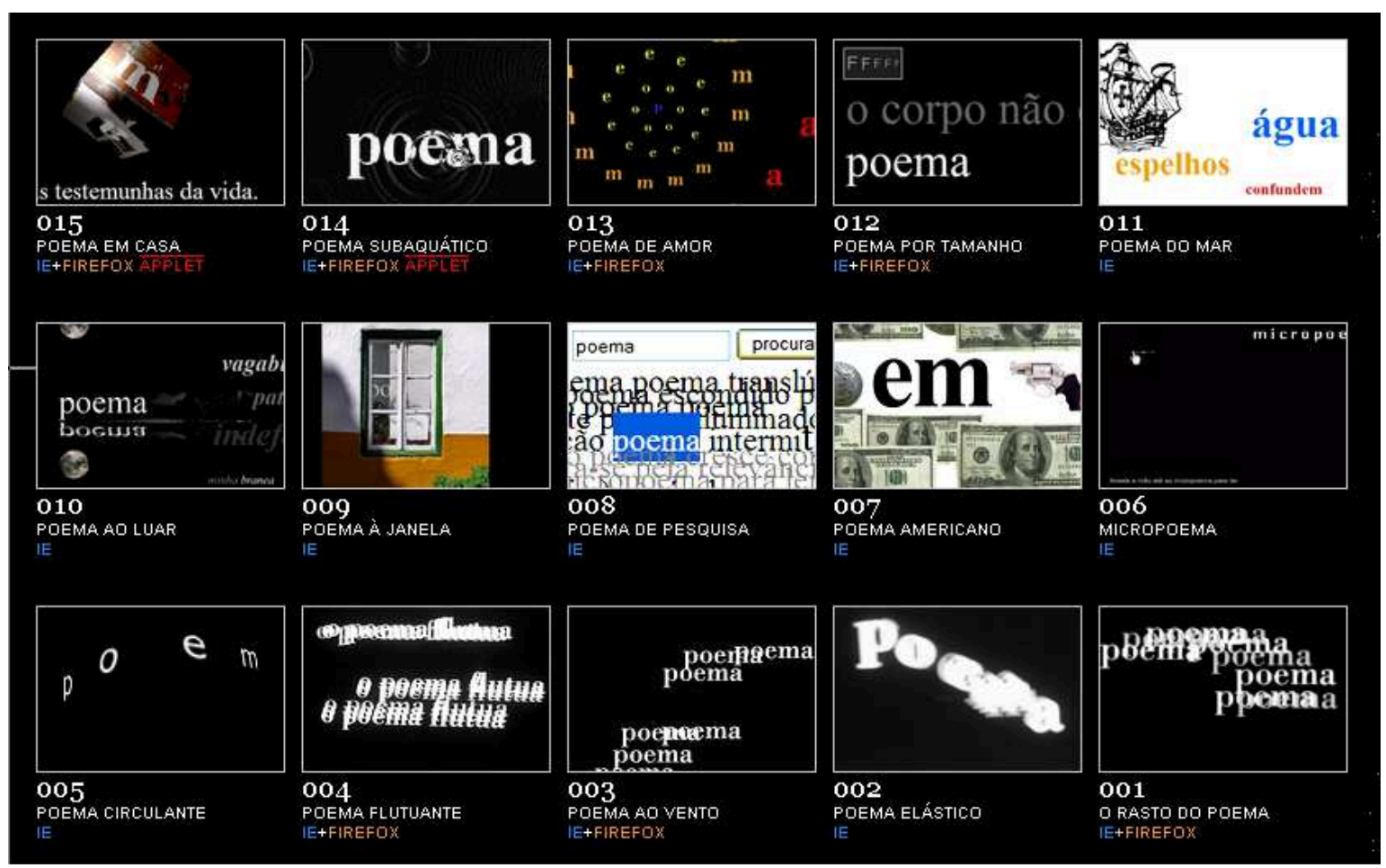

Figura 6. Antero de Alda, scriptpoemas, http://anterodealda.com/scriptpoemas.htm. Data de publicação: 2000-2010 [captura de ecrã].

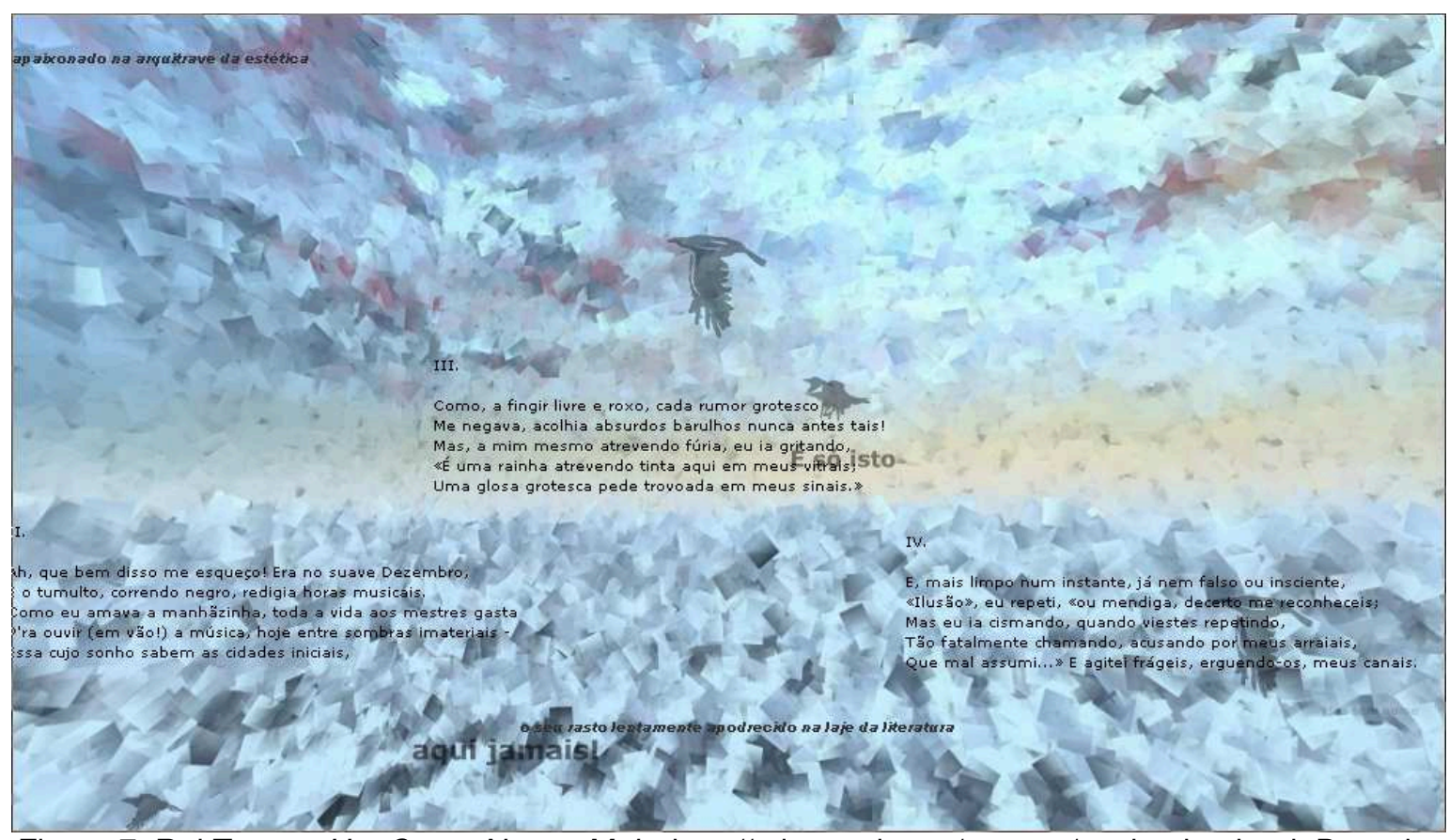

Figura 7. Rui Torres, Um Corvo Nunca Mais, http://telepoesis.net/pessoa/navigation.html. Data de publicação: 2010 [captura de ecrã]. 
Os sete exemplos referidos não se distinguem apenas pelo grau electrónico das respectivas inscrições tecnológicas, mas também pelos usos da linguagem e dos discursos poéticos e pela auto-representação das respectivas práticas no conjunto das práticas poéticas da web. Se em alguns casos é visível um programa criativo explícito de apropriação expressiva das propriedades materiais do meio e de crítica da língua, noutros casos a comunicação interpessoal e a sociabilidade mediada pela escrita e publicação em rede tende a ser predominante. Do conjunto muito significativo de práticas poéticas individuais e colectivas recenseadas por este levantamento de blogues, sítios web e revistas, é possível enunciar algumas hipóteses sobre as interacções entre o desenvolvimento de literacias digitais e os campos literários e culturais.

\section{Campos literários e culturais e o espaço de escrita electrónico}

Surgiram ainda nas décadas de 1980 e de 1990 as primeiras revistas de poesia em linha. Os seus editores mostravam-se cientes da novidade do meio como uma forma de publicação que transcendia as dificuldades de distribuição das pequenas editoras, pensando no novo meio sobretudo enquanto canal de difusão. $O$ hipertexto - que neste momento inicial consistia sobretudo na construção de ligações entre documentos constituídos por caracteres alfanuméricos - e a comunicação remota assíncrona tornaram-se entretanto um novo recurso para a criação de comunidades dispersas de escritores e leitores. As primeiras experiências tiveram lugar em universidades, particularmente nos Estados Unidos e no Canadá, já que grande parte da tecnologia estava a ser desenvolvida institucionalmente. ${ }^{7}$

\footnotetext{
7 Entre os centros pioneiros dedicados à investigação da experimentação literária com a tecnologia digital, refiram-se o Center for Literary Computing (West Virginia University; http://www.clc.wvu.edu/, criado em 1991), o Electronic Poetry Center (SUNY, Buffalo, http://epc.buffalo.edu/, criado em 1995) e a Electronic Literature Organization (http://www.eliterature.org, criada em 1999, na UCLA; entre 2006 e 2010, com sede na Universidade de Maryland; e desde 2011, com sede no MIT, Cambridge, MA). Em França, o Laboratoire Paragraphe, da Universidade de Paris 8, desenvolve também atividade de investigação e experimentação artística e literária digital desde a década de 1990. Em Portugal, refira-se o Centro de Estudos sobre Texto Informático e Ciberliteratura (CETIC), Universidade Fernando Pessoa, Porto (http://cetic.ufp.pt/; criado no final da década de 1990).
} 
Quando se formalizaram e estandardizaram os protocolos de comunicação entre redes e de transferência de ficheiros, teve início a expansão das redes hipertextuais de documentos. A Internet alarga-se para fora das universidades e de outros contextos institucionais, incluindo o militar, e permeia rapidamente todos os espaços da vida social, económica, política e privada. Em poucos anos, o meio expande-se e passa a incorporar grande parte das áreas da vida social, remediando as tecnologias de comunicação anteriores (livro, registo sonoro, fotografia, cinema, rádio, televisão, telefone, telefax, etc.). $O$ aumento da capacidade de processamento e de transmissão e a criação de aplicações de edição e publicação multimédia levou a que, nos inícios da década de 2000, a web começasse a tomar a configuração predominantemente multimodal que a caracteriza actualmente.

Até o início da década de 2000, a maioria das ferramentas ainda dependia de webmasters e editores, que realizavam o tradicional papel de guardiões dos espaços de publicação. Com o avanço da chamada Web 2.0, a intermediação de webmasters e editores foi gradualmente reduzida, e a ecologia da publicação substancialmente alterada à medida que wikis e weblogs se generalizavam. Enquanto a maioria dos sítios web iniciais dependia do controle de um editor de conteúdos, que poderia ser também editor web, agora um número crescente de sítios passa a funcionar como fóruns públicos de edição aberta, nos quais é possível publicar informação sem conhecimentos técnicos específicos. A mediação passa a ser feita predominantemente pelas próprias plataformas de acesso aberto e pelos modelos e funcionalidades de publicação oferecidos, sem necessidade de recurso a aplicações ou a codificação específica.

Ao mesmo tempo, com o aumento da capacidade de processadores e das redes de transmissão, a materialidade electrónica tornava-se predominantemente multimédia, com vídeos, imagens e ficheiros de som partilhados e interligados a um ritmo crescente. Assim, o espaço de escrita electrónico estritamente alfanumérico transformou-se progressivamente num ambiente hipermédia 
multimodal, repleto de milhares de novas aplicações para a criação e manipulação de todo o tipo de objectos digitais. Além disso, muitas das novas ferramentas são ao mesmo tempo ferramentas de software social, concebidas para generalizar telecomunicações síncronas e assíncronas, e para recriar no espaço virtual muitas das interacções face-a-face de espaços físicos locais.

O texto breve, com algumas centenas de palavras, torna-se numa das unidades de escrita e de leitura encorajadas quer pela imediaticidade do acto de publicação do novo meio, quer pelo salto de segmento em segmento e de página em página favorecido pela hiperligação. Este modo de escrita e de publicação permitiu também uma generalização do acto de escrever publicamente, uma vez que encorajava a forma breve, que não requeria o grande investimento de tempo em actos de revisão e reescrita, característicos das formas mais longas. A socialização da escrita e da publicação é outra das consequências evidentes da conectividade permanente nas sociedades da informação em rede. O uso do espaço electrónico para a escrita e leitura de poesia tem de ser entendido dentro deste agregado de possibilidades e transformações tecno-sociais e tecnoculturais. A nossa análise mostra que o descentramento dos modos de publicação criado pelo espaço de escrita digital deve ser analisado não apenas em relação aos modos impressos, mas também em relação à transformação e expansão do próprio espaço de publicação electrónica.

A expansão progressiva da esfera pública electrónica, em particular à medida que as principais instituições sociais alargavam a sua identidade a um corpo de ficheiros e endereços acessíveis via internet, significa que a maioria das estruturas do espaço social se reconstitui dentro da ecologia dos novos média. Os grandes órgãos de comunicação social (imprensa, rádio, televisão), por exemplo, foram das primeiras instituições a criarem uma presença permanente na internet. O espaço público electrónico tem de ser visto como extensão do espaço social em geral: reflecte a classe, o capital simbólico, o capital financeiro e o discurso, ou seja, as categorias que estruturam formas, discursos e práticas sociais. $O$ espaço electrónico e as representações em linha tornaram-se meios 
comunicacionais tão importantes que as principais instituições políticas, económicas, administrativas e educacionais rapidamente alargaram a sua presença e o seu poder a esta extensão da esfera pública.

Com efeito, os meios electrónicos determinam cada vez mais o ambiente comunicacional e burocrático da sociedade contemporânea, uma vez que a textualidade electrónica sustenta o tecido administrativo e político das sociedades de alta tecnologia. Os ambientes electrónicos em rede são também uma das novas formas de disciplinar o sujeito, e um dos novos sistemas de controlo social e político. A base de dados tornou-se a forma simbólica dominante não apenas nos processos artísticos e científicos, mas nos processos de gestão e organização social. Este poder omnipresente da tecnologia digital significa que as formações sociais e instituições incorporaram rapidamente a tecnologia dos novos média nas suas estruturas de poder. O discurso digital, isto é, o conjunto de representações verbais e audiovisuais que justifica a crescente digitalização das sociedades, constitui mesmo uma das formas ideológicas nucleares da actual ordem política das sociedades da informação.

O campo literário fornece um subdomínio específico para observar tanto os efeitos de um novo meio sobre os modos de reconhecimento consagrados pela publicação impressa, como a replicação dos modos de legitimação num novo ambiente tecnocultural. O espaço electrónico torna-se um espelho de outros espaços de publicação e distribuição, ou seja, o espaço electrónico enquanto meio não pode ser descrito como uma alternativa por si só, como parece ter sido no período inicial da world wide web, quando a sua presença era mais circunscrita e o seu uso social mais limitado. Quando apareceu pela primeira vez, criou uma capacidade de publicação que concorria com as práticas impressas, mas essa capacidade de funcionar como uma alternativa tem diminuído consideravelmente. Os marcadores do campo literário electrónico são cada vez mais aqueles que marcam o campo literário em geral. ${ }^{8}$

\footnotetext{
${ }^{8}$ A presença crescente das instituições literárias no espaço de publicação electrónico pode ser exemplificada com a edição dos arquivos integrais de publicações como a Colóquio/Letras
} 
Apesar de toda a actividade e criatividade que documentámos, a visibilidade social das práticas em linha depende, em larga medida, de um mesmo conjunto de instituições sociais e práticas discursivas. Quanto ao blogue enquanto ferramenta de escrita e modo de publicação, podemos dizer que não é um género, embora existam certas características tipológicas que têm sido identificadas como genéricas, particularmente aquelas que reflectem a estrutura de arquivo pré-definido de entradas de diário ou as que promovem o comentário aos textos lidos. Apesar disso, o blogue permite integrar e experimentar com múltiplos géneros e formas (ficcionais, poéticos, dramáticos, jornalísticos, ensaísticos, autobiográficos, etc.). Uma análise literária, estética e discursiva teria de começar com as características capacitadoras e limitadoras da própria plataforma e dos modelos de publicação enquanto estruturas organizacionais e dispositivos retóricos.

De que modo o espaço de escrita electrónico reflecte as estruturas de poder e capital simbólico associado a outros meios e a outros espaços sociais? A popularidade e o número de leitores, por exemplo, indicam a reputação de um determinado blogue, reflectindo um capital simbólico que tem origem noutros meios. Rita Alberto descreve os processos de absorção através dos quais as vozes na imprensa legitimam a escrita nos blogues por referência às hierarquias de valor literário dominantes (Alberto, 2009, pp. 43-44). Deste modo, o espaço de escrita electrónico não é tão descentrado ou não-estruturado como a natureza associativa da ligação ou a liberdade de acesso poderia implicar. Apesar do efeito de nivelamento das associações aleatórias, existem várias hierarquias a estruturar os modos de recepção e leitura dos ficheiros. Essas hierarquias são

(http://www.coloquio.gulbenkian.pt/, publicados em linha entre 2006 e 2008); com a edição parcial de suplementos de crítica cultural, como o ípsilon, do jornal Público (http://ipsilon.publico.pt/, publicado em linha desde 2008), ou com o blogue da revista Ler (http://ler.blogs.sapo.pt/, em linha desde 2008); com os vários projectos públicos e comerciais de Bases de Dados Textuais e de Bibliotecas Digitais, por exemplo, a Biblioteca Digital Camões do Instituto Camões (http://cvc.instituto-camoes.pt/conhecer/biblioteca-digital-camoes.html, em linha desde 2009) e com a presença maciça do mercado editorial. A reprodução digital permite alargar o corpo de autores e de textos distribuídos, mas reflecte, na sua organização e estruturação, o prestígio cultural e o poder económico das instituições de produção e de comunicação cultural e literária. 
internas e externas ao espaço de escrita electrónico. Internas, porque estão dependentes de novos mecanismos de legitimação e reconhecimento, tais como as ligações, a contagem de visitas e os comentários. Externas, porque são uma extensão do prestígio e do poder social que tem origem noutros espaços sociais e mediais, e que geram comportamentos de reprodução cultural.

Jornais diários e semanários, bem como revistas, rádios e canais de televisão agregam e patrocinam um conjunto significativo de blogues sobre temáticas diversas. O capital simbólico das instituições de comunicação contribui assim para construir a reputação e as comunidades de leitores daquelas publicações electrónicas. ${ }^{9}$ Isto significa que no espaço electrónico está também marcada a estrutura das posições que os agentes de um campo podem ocupar. A possibilidade de passar de uma pequena comunidade localizada de leitores, frequentemente equivalente a uma rede de amigos, para uma comunidade mais alargada depende dos processos de valorização simbólica mantidos pelas instituições de mediação (órgãos de comunicação, crítica literária, escolas e universidades, entre outras).

O processo de trocas entre a escrita pessoal publicada exclusivamente no blogue e a escrita publicada em jornal, em revista e em livro, por exemplo, reflecte a dinâmica da relação entre o capital simbólico da escrita impressa através de canais institucionais (equivalente a permanência, prestígio e reconhecimento) e o capital simbólico da escrita electrónica autopublicada (equivalente a efemeridade, pouco prestígio e baixo reconhecimento). Em alguns dos blogues de escrita ou de crítica literária é possível observar o modo como esta dinâmica de trocas permite aos autores construir determinada identidade individual na blogosfera, mas com uma voz que não consegue ser independente da mediação das restantes

\footnotetext{
${ }^{9}$ Vejam-se, por exemplo, as listas de 'blogues do Público' e de 'blogues convidados do Público' (http://static.publico.clix.pt/sites/blogues/default.aspx) ou a lista equivalente do Jornal de Notícias (http://www.jn.pt/blogues/). A concepção de blogue como agente numa rede social, proposta por Rita Alberto (2009, p. 19), ajuda a descrever a sua função na ecologia global de publicação da escrita.
} 
instituições literárias (jornais, revistas e livros; escolas e universidades). ${ }^{10}$ Por outro lado, a recolha em livro impresso de textos publicados originalmente em blogues, confirma a persistência do ascendente cultural do impresso na produção das categorias 'literário' e 'poesia'. ${ }^{11}$

Compreender se há algo de específico na estruturação do espaço de escrita electrónico implica descrever as relações entre as duas esferas de comunicação. Para isso precisamos de uma boa descrição da autonomia relativa e da dependência mútua entre os meios impressos e os meios electrónicos. Podemos dizer que a estrutura dos campos económicos e culturais se reconstitui assimilando os novos média. À medida que a cultura se torna predominantemente digital, os novos média são apropriados pelas estruturas hegemónicas da sociedade. Apesar disso, podemos dizer que, pelo menos por um determinado tempo e dentro de contextos sociais e locais específicos, os meios electrónicos incentivam e favorecem práticas que funcionam em alternativa ou em concorrência com outros média e com o respectivo poder social. A disponibilidade dos meios electrónicos é útil em especial para um conjunto de práticas literárias para as quais não havia mercado de impressão ou apenas um mercado muito pequeno. $^{12}$

No entanto, quando os média electrónicos se tornam ubíquos, as práticas e instituições dominantes colonizam a esfera da escrita electrónica, trazendo consigo o seu capital económico e simbólico. A posição marginal e subalterna de novos projectos de escrita (poesia, ficção, ensaio, jornalismo) tende pois a reproduzir-se no espaço electrónico. A dificuldade em criar circuitos económicos

\footnotetext{
${ }^{10}$ Veja-se, por exemplo, a função que os textos publicados periodicamente no jornal Público têm nos blogues de Eduardo Pitta, 'Da Literatura' (http://daliteratura.blogspot.com/, em linha desde 2005) e de Isabel Coutinho, 'Ciberscritas' (http://www.ciberescritas.com/, em linha desde 2008), na construção da voz autoral do crítico.

${ }^{11}$ A vinculação da publicação impressa à identidade 'poeta' foi documentada por Rita Alberto no discurso de vários/as entrevistados/as (2009, pp. 69-77).

${ }_{12}$ Seria relevante, a este propósito, observar a relação entre a passagem para os meios electrónicos e a continuidade, ou não, da produção de revistas impressas de poesia em pequenas editoras independentes. A persistência de uma actividade intensa de impressão sobre papel, documentada igualmente no âmbito deste projecto, parece indicar a permanência do impresso na capitalização simbólica do escrito.
} 
sustentáveis, sobretudo para projectos que impliquem grande quantidade de trabalho de edição e de preparação de ficheiros, limita a possibilidade de uma publicação continuada. Sob este aspecto, a economia laboral da revista em linha não é significativamente diferente da economia laboral da revista impressa, já que a publicação coordenada de contributos de um colectivo com uma certa dimensão depende de uma grande quantidade de trabalho e de recursos económicos avultados.

\section{Conclusões: mediação, reprodução, transformação}

Os meios electrónicos proporcionam um espaço material de experimentação literária e social, ao alterarem a economia da produção, da distribuição e da recepção da escrita. Este espaço de escrita electrónico oferece novas ferramentas a escritores e leitores, de que o weblog se constitui como a prática mais comum. A escrita adquire certas propriedades do novo meio, como a hipertextualidade e a multimodalidade, redefinindo as suas convenções em função das propriedades das aplicações digitais. Um conjunto significativo de autores e autoras, de forma individual ou em pequenos colectivos, usa estas ferramentas para explorar criativamente a linguagem na sua interacção com outras dimensões materiais e sociais da textualidade electrónica.

Verificámos ainda que as redes de relações criadas pela escrita e publicação de poesia em hipertexto tendem a ser determinadas pelos modos de percepção e de legitimação instituídos no campo literário. Assim, o reconhecimento social e o impacto cultural das práticas poéticas em rede dependem das instituições literárias, culturais e educacionais, tais como escolas e universidades, jornais e revistas, e outros meios de comunicação. Apesar da multiplicidade de práticas de escrita desencadeadas pelas literacias digitais, persistem percepções altamente hierarquizadas do valor e da função da 'poesia', incluindo a necessidade de legitimação por via de modos de reconhecimento ancorados na cultura impressa. 
Uma linha adicional de investigação, que não seguimos, teria que observar os modos através dos quais os espaços geográficos e sociais interagem com o espaço em rede: como é que a inscrição local se vê reflectida, desviada e transformada pelas práticas em linha? As trocas comunicativas são determinadas por outros tipos de redes sociais ou promovem elas próprias um espaço mediado que é efectivamente independente da localização geográfica e da posição social dos seus membros? As redes electrónicas reforçam ou modificam o funcionamento das redes sociais nos processos de produção e recepção literária? A maioria destas questões só pode receber uma resposta aproximada e provisória para aquilo que é um processo tecnocultural em curso, de carácter multiestratificado e policêntrico.

A nossa investigação revelou um conjunto disperso de inúmeras actividades de escrita, publicação e leitura, levadas a cabo por muitos indivíduos e grupos, em todas as regiões do país, mostrando a importância da Internet como um novo espaço material e social para a poesia e para a poética enquanto modos particulares de intercâmbio comunicativo e de experimentação com a linguagem, com o discurso e com a mediação tecnológica em geral.

\section{WEB POETRY: PORTUGUESE POETRY IN BLOGS AND SITES}

ABSTRACT: This article is based on a survey of the use of networked electronic media for the production and publication of poetry in Portugal. We consider both digital poetry (i.e., poetry dependent on specific programming codes and software applications) and poetry that is published and distributed electronically. Our approach combines a medium-specific analysis of formal properties of the works and publications with a sociological analysis of the social relations of production across various groups and communities. We are interested in seeing how actual writing practices have appropriated the digital medium for creating, publishing, and distributing poetry. The electronic writing space offers an alternative channel to the more expensive medium of printed paper. It also extends the materialities of literature into intermedia forms and practices that take advantage of the media-convergent capabilities of digitality. We further attempt to understand the social dynamics of this particular literary field and its networks of interaction, as they reflect, challenge, or transform the wider cultural field.

KEYWORDS: Portuguese electronic poetry. Online publication. Poetry blogs. Literary field. Social networks. 


\section{Referências}

AARSETH, Espen. Cybertext. Perspectives on Ergodic Literature. Baltimore: Johns Hopkins University Press, 1997.

ALBERTO, Rita. mur.mur(i)o. poetas na blogosfera. Coimbra: Faculdade de Economia da Universidade de Coimbra [tese de mestrado], 2009.

ANDROUTSOPOULOS, Jannis; MICHAEL, Beißwenger (orgs.). Data an Methods in Computer-Mediated Discourse Analysis. In: Language@Internet. Vol. 5, 2008. Disponível em: http://www.languageatinternet.de/.

ANTONIO, Jorge Luiz. Poesia Electrônica: Negociações com os Processos Digitais. São Paulo: FAPESP; Veredas e Cenários, 2008.

ARMAND, Louis (org.). Contemporary Poetics. Evanston: Northwestern University Press, 2007.

BARBOSA, Pedro. Ciberliteratura: Criação Literária e Computador. Lisboa: Edições Cosmos, 1996.

BERNSTEIN, Charles. Making Audio Visible: The Lessons of Visual Language for the Textualization of Sound. In: Text, vol. 16, 2006, p. 277-289.

BOLTER, Jay David; GRUSIN, Richard. Remediation: Understanding New Media. Cambridge: MIT Press, 2000.

BOOTZ, Philippe. Digital Poetry: From Cybertext to Programmed Forms. In: PETERSON, Tim (org.). Leonardo Electronic Almanac, Special Issue: New Media and Poetics, vol. 14. 5-6, Sept 2006. Disponível em: http://www.leoalmanac.org/journal/vol_14/lea_v14_n05-06/pbootz.html

CAYLEY, John. Time Code Language: New Media Poetics and Programmed Signification. In; MORRIS, Adalaide; SWISS, Thomas (eds.). New Media Poetics: Technotexts, and Theories. Cambridge: MIT Press, 2006. p. 307-334.

. Weapons of the Deconstructive Masses (WDM): Whatever Electronic Literature May or May Not Mean. In: Revista de Estudos Literários, Vol. 2, 2002, p. 25-56.

CRYSTAL, David. Language and the Internet. Cambridge: Cambridge University Press, 2006.

DRUCKER, Johanna. Graphical Readings and the Visual Aesthetics of Textuality. In: Text, Vol. 16, 2006, p. 267-276. 
SpecLab: Digital Aesthetics and Projects in Speculative Computing. Chicago: Chicago University Press, 2009.

FUNKHOUSER, Chris. Prehistoric Digital Poetry: An Archaeology of Forms, 1959-1995. Tuscaloosa: University of Alabama Press, 2007.

Digital Poetry: A Look at Generative, Visual, and Interconnected Possibilities in its First Four Decades. In: SCHREIBMAN, Susan; SIEMENS, Ray (eds.). A Companion to Digital Literary Studies. Oxford: Blackwell, 2008. p. 318-335.

GITELMAN, Lisa. Always Already New: Media, History, and the Data of Culture. Cambridge: The MIT Press, 2008.

GLAZIER, Loss Pequeño. Digital Poetics: The Making of E-Poetries. Tuscaloosa: University of Alabama Press, 2008.

Code as Language. In: PETERSON, Tim (org.). Leonardo Electronic Almanac, Special Issue: New Media and Poetics, Vol. 14. 5-6, Sept 2006. Disponível em: http://www.leoalmanac.org/journal/vol_14/lea_v14_n0506/lglazier.html.

GURAK, Laura J. et al. (orgs.). Into the Blogosphere: Rhetoric, Community, and Culture of Weblogs. 2004. Disponível em: http://blog.lib.umn.edu/blogosphere/.

HANSEN, Mark B.N. Bodies in Code: Interfaces with Digital Media. London: Routledge, 2006.

New Philosophy for New Media. Cambridge: The MIT Press, 2006.

HAYLES, N. Katherine. Writing Machines. Cambridge: The MIT Press, 2002.

. My Mother Was a Computer: Digital Subjects and Literary Texts. Chicago: University of Chicago Press, 2005.

Electronic Literature: New Horizons for the Literary. Notre Dame: University of Notre Dame, 2008.

How We Think: Digital Media and Contemporary Technogenesis. Chicago: University of Chicago Press, 2012.

KIRSCHENBAUM, Matthew G. Mechanisms: New Media and the Forensic Imagination. Cambridge: The MIT Press, 2008.

KITTLER, Friedrich A. Gramaphone, Film, Typewriter. Stanford: Stanford University Press, 1999.

Optical Media. Cambridge: Polity Press, 2010. 
KRESS, Gunther. Literacy in the New Media Age. London: Routledge, 2004.

MANOVICH, Lev. The Language of New Media. Cambridge: The MIT Press, 2001.

Software Takes Command. 2008. Disponível em: http://lab.softwarestudies.com/2008/11/softbook.html

MARINO, Mark C. The ppg256 Perl Primer: The Poetry of Techneculture. In: ELP emerging language practice, Dept of Media Culture, SUNY, Buffalo, Issue 1, 2010. Disponível em: http://epc.buffalo.edu/ezines/elp/issue-1/ppg256.php.

MORRIS, Adalaide; SWISS, Thomas (orgs.). New Media Poetics: Contexts, Technotexts, and Theories. Cambridge: The MIT Press, 2006.

MORRISON, Aimée. Blogues and Blogging: Text and Practice. In: SCHREIBMAN, Susan; SIEMENS, Ray (orgs.). A Companion to Digital Literary Studies. Oxford: Blackwell, 2008, p. 369-388.

PERLOFF, Marjorie. Screening the Page/ Paging the Screen: Digital Poetics and the Differential Text. In: MORRIS, Adalaide; SWISS, Thomas (orgs.). New Media Poetics: Contexts, Technotexts, and Theories. Cambridge: The MIT Press, 2006, p. 143-164.

PORTELA, Manuel. Flash Script Poex: A Recodificação Digital do Poema Experimental. In: Cibertextualidades, Vol. 3, 43-57, 2009.

The Text in the Machine, and the Machine in the Text. In: Digital Humanities Quarterly, Vol. 4, n. 1, Summer 2010. Disponível em: http://67.207.129.15:8080/dhq/vol/4/1/000087/000087.html.

. Between Code and Motion: Generative and Kinetic Poetry in French, Portuguese, and Spanish. In: Romance Notes, Vol. 51.3, p. 305-333, 2011.

. Autoauthor, Autotext, Autoreader: The Poem as Self-Assembled Database. In: Writing Technologies, Vol. 4, p. 43-74, 2012.

SIMANOWSKI, Roberto; SCHÄFER, Jörgen; GENDOLLA, Peter (orgs.). Reading Moving Letters: Digital Literature. In: Research and Teaching. A Handbook. Bielefeld: transcript Verlag, 2010.

STEFANONE, Michael A.; JANG, Chyng-Yang. Writing for Friends and Family: The Interpersonal Nature of Blogues. In: HERRING, Susan (org.). Journal of Computer-Mediated Communication, Vol. 13.1, October 2007. Disponível em: http://jcmc.indiana.edu/vol13/issue1/stefanone.html. 
WARDRIP-FRUIN, Noah. Expressive Processing: Digital Fictions, Computer Games, and Software Studies. Cambridge: The MIT Press, 2009.

WATTEN, Barrett. Poetics in the Expanded Field: Textual, Visual, Digital.... In: MORRIS, Adalaide; SWISS, Thomas (orgs.). New Media Poetics: Contexts, Technotexts, and Theories. Cambridge: The MIT Press, 2006, pp. 335-370.

ZIELINSKI, Siegfried. Deep Time of the Media: Toward an Archaeology of Hearing and Seeing by Technical Means. Cambridge: The MIT Press, 2006.

Texto recebido em 31/10/2012. 